\title{
MUJERES IMAGINANDO NUEVAS CARTOGRAFÍAS EN LA ARGENTINA DEL POSTMILENIO
}

\author{
María José Punte \\ Pontificia Universidad Católica Argentina / Universidad de Buenos Aires \\ Buenos Aires, Argentina \\ majo.punte@gmail.com
}

RESUMEN / ABSTRACT

Hablar de "sujetos nómades" para referirse a las generaciones de escritoras del nuevo milenio, ya resulta insuficiente. Estamos ante subjetividades y cuerpos acostumbrados a atravesar diversos tipos de fronteras: físicas, lingüísticas, de géneros discursivos. El desafío actual parece ser la tentación de habitar las fronteras y de establecer ahí un "hogar en la encrucijada" (Bauman). En ese juego de articulación de los lugares fronterizos, una serie de escritoras argentinas exhiben otras formas de concebir el espacio, hacia una cartografía hecha de los restos coleccionados por el paso de lugares ajenos entre sí; una temporalidad concebida como un collage de husos horarios; un lenguaje perdido en las traducciones. En este trabajo serán abordadas tres obras: En el hotel cápsula (2017) de Lucía Puenzo, Algún lugar (2017) de Paloma Vidal y $V$ (2017) de Mariana Docampo.

PALABRAS CLAVE: literatura argentina, espacialidad, cuerpos, generación postmilenio.

\section{WOMEN IMAGINING NEW CARTOGRAPHIES \\ IN THE POST-MILLENNIAL ARGENTINE}

Referring to the generation of writers of the new millennium as "nomadic subjects", it has become already insufficient. Bodies and subjectivities are used to overstep different types of boundaries: physical, linguistic, discursive genres. The current challenge for these writers seems to be not the desire to cross borders, as the temptation of inhabiting them, establishing a "home on the crossroads" (Bauman). In this game of the articulation of these boundaries, a group of three Argentine writers, show us in their writings a contemporary way of conceiving space, as a collage of different places that don't belong to each other; temporality is conceived as an assembly of time zones; language, as lost in translations. Three works will be addressed: En el hotel cápsula (2017) by Lucía Puenzo, Algún lugar (2017) by Paloma Vidal and V (2017) by Mariana Docampo. 
KEYWORDS: argentine literature, space, bodies, postmillennial generation.

Recepción: 31/10/2019

Aprobación: 29/01//2020

\section{PUNTO DE PARTIDA: LAS COINCIDENCIAS}

Intentar hacer una cartografía en torno de la literatura del presente, más allá del campo en el que decidamos concentrarnos, se ha vuelto una empresa tan quimérica como tentadora. ¿Por dónde empezar a trazar los ejes o los puntos nodales desde los cuales dibujar algo así como un mapa? En lo que concierne a la literatura argentina actual, sobran ejemplos que podrían llegar a ser representativos de la temática propuesta por este dossier en torno a las escritoras latinoamericanas de comienzos de este mileno. Para este trabajo optamos por tres autoras que han desplegado obras muy diferentes y, sin embargo, tienen los pies bien plantados en ciertas preocupaciones que atraviesan los debates de lo contemporáneo. Lo primero que se percibe como un rasgo en común es la conciencia en ellas de producir obras en un mundo intercontectado, al que solemos llamar global o mundializado, en donde las comunicaciones y las traslaciones en el espacio se han facilitado o incrementado hasta generar un determinado modo de ciudadanía que no se siente encorsetada por las fronteras nacionales. Sabemos que este tipo de delimitaciones aún condiciona la existencia de todo sujeto en la actualidad, dando lugar a ciudadanías de distintas clases, así como a la figura del desclasado ${ }^{1}$. Sin embargo, la posibilidad de viajar y de moverse por el planeta aparece como una de las marcas indiscutibles en sus obras, tematizadas desde posiciones variadas.

Vamos a abordar a tres autoras de la misma franja generacional: Lucía Puenzo, nacida en 1976, Paloma Vidal, en 1975 y Mariana Docampo, en 1973. Las tres han escrito textos literarios, sobre todo novelas y cuentos.

1 Esta certeza reviste una de las preocupaciones centrales de Bauman quien, al pensar la globalización, constata los modos en que se estratifica la sociedad de consumo o posmoderna. La movilidad, su mayor o menor grado de posibilidad, es lo que produce las escalas actuales de estratificación entre quienes tienen la libertad de moverse (los globalmente móviles) y lo que se ven obligados a ello, o a moverse en condiciones que no desean ni eligen (localmente sujetos). A eso se suman los sistemas de fronteras y visados. Esta distinción le permite hablar de dos paradigmas en relación con las vivencias de la movilidad: los turistas y los vagabundos (La globalización 103-133). 
Aunque una de las características a tener en cuenta son los modos en que, a partir de la escritura, sus trabajos van desdibujando las fronteras genéricas o de los campos artísticos, como se verá en los ejemplos que serán analizados a continuación. En ese sentido es que la escritura literaria no es el único terreno al que ciñen sus obras. Recurriendo al concepto de "modernidad líquida" que propone Zygmunt Bauman, se puede decir que para estas escritoras ya no se hace viable un modelo de escritura que siga los parámetros de lo "pesado" o del hardware. Delimitar una frontera deja de ser una "obsesión", y la "técnica de poder" a la que se apunta es la de "la huida, el escurrimiento, la elisión, la capacidad de evitar" (Bauman, Modernidad líquida 17); estas escritoras buscan allí la potencia.

Lucía Puenzo es, además de escritora, guionista y directora de cine. Por momentos, incluso, parece ser mejor conocida ante un público amplio por sus películas más que por sus novelas. Paloma Vidal además de escritora y profesora universitaria, es editora de la revista digital bilingüe Sala Grumo e incursiona en el terreno de la performance. Mariana Docampo también ha realizado labores como editora, como guionista de cine, pero además baila tango y dirige una milonga queer. El hecho de publicar novelas parece funcionar como un núcleo que atrae por su fuerza centrípeta la legitimidad de la producción de estas autoras. Esto las convierte en escritoras, lo cual sigue teniendo su peso en el campo cultural. Pero lo que interesa de sus textos para el siguiente análisis no es tanto ver posibles contaminaciones o préstamos entre la textualidad y las otras variantes de la expresión artística, sino pensar cómo es que se mueven estas subjetividades del presente, sus rutas, así como los espacios de permanencia. En realidad, estas escrituras parecen más a gusto habitando la frontera, lo cual no quiere decir que estén del todo cómodas en ella. Lo cierto es que hay un deseo de merodear por los "espacios vacíos", que Bauman define como lugares a los que no se les adscribe ningún sentido, sobrantes luego del mapeo mental y que no han sido cartografiados (112).

Un caso particular en este grupo es el que representa Paloma Vidal. Técnicamente, ella no es una autora "argentina". ¿Por qué incluirla entonces?

\footnotetext{
Más adelante, Bauman reforzará este término de manera contundente en un crescendo significativo: "El territorio fue una de las mayores obsesiones modernas, su adquisición fue una de sus mayores compulsiones y la protección de las fronteras llegó a convertirse en una de las adicciones modernas más ubicuas, inflexibles y permanentes" (122, las cursivas me pertenecen).
} 
Suele aparecer mencionada como "argentino-brasileña" para saldar de alguna manera su doble adscripción nacional. Si bien nació en Argentina, fue al exilio siendo muy pequeña con sus padres a Brasil, en donde vive actualmente ${ }^{3}$. Más allá de que ejerce una trashumancia que es ya moneda corriente para buena parte de su generación, su hogar o lugar de pertenencia parece estar en Brasil, algo que en gran medida tematiza en su primera novela Algún lugar ${ }^{4}$. No es la circunstancia de vivir en Brasil y definirse como brasileña lo que nos hace dudar frente a su inclusión en un canon nacional, sino el hecho de escribir sus textos en portugués. Tal vez este ejemplo nos sirva para repensar la vinculación entre una literatura nacional y la lengua, ya que las fronteras dibujadas en los mapas no anulan el bi- o multilingüismo en el que viven muchas personas. Lo cierto es que Paloma Vidal escribe en portugués y traduce ella misma o hace traducir sus textos al castellano ${ }^{5}$. Su caso es emblemático del escritor que vive en más de una lengua, situación sobre la que reflexiona Sylvia Molloy en su iluminador ensayo Vivir entre lenguas. Ir y venir de un idioma al otro deja evidentes marcas en la escritura. En el caso de Paloma Vidal, además, plantea cuestiones en torno de la memoria, los orígenes y las búsquedas identitarias ${ }^{6}$.

3 En su artículo "Narrativas da diáspora feminina contemporánea", las autoras hacen notar que Vidal no se hizo nacionalizar brasileña a pesar de vivir en Brasil desde los dos años, con lo que se subraya esta elección de transitar por dos culturas diversas (Correia Muzi et al. 440).

Consigno aquí mi agradecimiento a Paloma Vidal que me hizo llegar su novela Algún lugar a través de su amigo y traductor Mario Cámara, que ofició de "mensajero".

Como es sabido, un ejemplo actual muy reconocido es el de la escritora Laura Alcoba (nacida en 1968) que vive en Francia desde los diez años, lugar al que se exilió con su familia y, por lo tanto, escribe sus novelas en francés, para luego ser traducidas al castellano.

6 Ilse Logie, al encarar este tema, sostiene que la reflexión en torno de la lengua que hace Paloma Vidal apunta a pensar ese núcleo común entre emigración y memoria, a partir del cual se recuerda el pasado para vislumbrar o imaginar un futuro. El bilingüismo contribuye a esta condición de identidad ambivalente, asumida por la narradora como discontinua y compleja. Siganevich, por su parte, piensa a Vidal dentro de un grupo junto con las escritoras Lina Meruane y Cynthia Rimsky con quienes comparte tanto la generación, como el hecho de ser viajeras de la mundialización. Las tres coinciden en recorrer mediante la escritura un territorio imaginario con el fin de recuperar retazos de las lenguas familiares, en un movimiento de búsqueda de los orígenes. Tanto Logie como Siganevich centran su análisis en Más al sur (2008). La vinculación entre migración y memoria, así como exilio y errancia está trabajado en Algún lugar a partir de autores postcoloniales como Edward Said por Correia Muzi et al. 
El caso de Lucía Puenzo resulta paradigmático de un sujeto contemporáneo que asume el vivir atravesando numerosas fronteras, llevando y trayendo sedimentos de un lado hacia el otro. No solo por el hecho de escribir novelas que luego transpone al cine, como es el caso de El niño pez y Wakolda. Su obra está tramada a partir de numerosos movimientos de transmigración, lo que supone en primera instancia viajes y travesías, pero también cambios de diversa índole, lo que ya ha sido estudiado por la crítica (Forné, González, Luengo). No es difícil distinguir en los textos de Puenzo la impronta de una literatura de fuerte cuño urbano, más allá de los lugares en donde se ubican las acciones. Tanto las problemáticas como las estéticas pueden ser percibidas como comunes a lectores globales. En cuanto a los temas, porque sus novelas se refieren a los cambios producidos en la familia moderna (en dirección a lo que puede ser considerado una familia posmoderna), que van de la mano del amplio espectro de cuestionamientos dirigidos al sistema patriarcal, así como de nuevos modos de inteligibilidad para la sexualidad. Abundan en sus textos personajes que proponen nuevas formas de habitabilidad y que configuran sujetos maleables, sujetos que resultan monstruosos porque se encuentran en una situación de liminalidad. Aparecen temáticas como el reconocimiento de la intersexualidad y la transexualidad, la visibilización de la lesbiana, y propuestas para comunidades familiares alternativas. En cuanto a lo estético, por su vinculación con la cultura de masas y la forma en que se coloca como tributaria de sus recursos, Puenzo se reconoce en cierta medida como heredera de Manuel Puig, algo que se hace patente en su predilección por el kitsch y por la sensibilidad camp con su "mal gusto"7.

La tercera autora elegida, Mariana Docampo, responde menos a este tipo de ciudadanía trotamundos y global, lo que no quiere decir que en sus textos no haya viajes. Lo que resulta atractivo de su obra es la forma en que pone en escena otro tipo de transhumancias, a partir de sujetos que se resisten a ser sujetados ${ }^{8}$. A lo largo de sus breves libros es imposible no percibir

7 Para un desarrollo pormenorizado de este tema, véase Punte, Topografías del estallido 69-82.

8 Mariana Docampo es licenciada en Letras por la Universidad de Buenos Aires. Publicó cuentos y novelas. Su novela El Molino (Bajo la luna, 2007) ganó el segundo premio del Fondo Nacional de las Artes. Desde el 2011 dirige la colección Las antiguas de la editorial Buena Vista, que se dedica a la publicación de las primeras escritoras argentinas. Es la fundadora del espacio Tango Queer y una de las organizadoras del Festival Internacional de Tango Queer en Buenos Aires. Es coguionista del largometraje Marilyn (Martín Rodríguez 
movimientos, no solo de aquellos que suponen la translación de materiales y que dan cuenta de cómo se van borroneando las fronteras. Resulta más que evidente en la novela $V$, que abordaremos en el tercer apartado. Se trata de un texto de difícil definición en donde los cruces de géneros textuales van delineando formas narrativas inéditas. En cierto modo, tiene un aire de "tratado", algo que aparece preanunciado en su libro anterior, Tratado del movimiento, en donde un lenguaje pretendidamente científico y un abordaje ensayístico de la materia narrada se presentan bajo el ropaje de "novela", desfigurando mediante un anamorfismo el pacto lector. Dentro de las preocupaciones contemporáneas que circulan en sus textos, se encuentra la que alerta sobre las debacles ecológicas de nuestro tiempo, aunque las reflexiones que abundan en sus páginas apuntan sobre todo a confrontarse con los modos en que la especie humana se vincula con las otras especies.

Hay un elemento que comparten los tres textos que han sido elegidos para trazar una ruta provisoria en esta cartografía literaria. Se trata de la coincidencia de la fecha de publicación, dato que en principio resulta tan fortuito como relativizable. Al fin y al cabo, la novela Algún lugar de Paloma Vidal se publicó por primera vez en lengua portuguesa en el año 2009. Pero su versión española es del 2017. Es la misma fecha de publicación de los relatos En el hotel cápsula de Lucía Puenzo y la novela $V$ de Mariana Docampo. En ese cruce no buscado, se genera una simultaneidad o una forma de superposición temporal que hace resaltar la contemporaneidad de la obra de estas tres autoras. Leer sus textos para intentar armar una figura a partir de ellos, supone una dinámica caleidoscópica. Si bien por momentos coinciden, no se superponen totalmente, dejando espacios libres a los costados. Esta lectura no va a agotar los textos. Los aborda, simplemente, para intentar pensar las movilidades de los sujetos contemporáneos, que no se limitan a ser la mera capacidad de trasladarse en el espacio.

Redondo, 2018) y coautora junto con Guillermo Gasió del libro de entrevistas Sara Facio. La foto como la pasión (Planeta, 2016). 


\section{ANVERSO Y REVERSO DE LA PANTALLA: EN EL HOTEL CÁPSULA DE LUCÍA PUENZO}

El caso de esta autora es muy particular, porque Lucía Puenzo dirige películas de cine además de escribir guiones cinematográficos y novelas ${ }^{9}$. Entre sus obras más sobresalientes se incluyen tres largometrajes de notable recepción internacional, más seis novelas. A estas se suma un volumen, En el hotel cápsula, con tres textos que podrían ser definidos como crónicas, pero que también pueden ser leídos como si fueran cuentos. Estos relatos oscilan entre un pacto de tipo autoficcional, de innegable verosimilitud, y un elemento ficticio, que transita siempre por los textos de la autora. La consecuencia de esa oscilación es que el lector se ve obligado a replantearse qué es lo que entiende por realismo, algo que reaparece en su última novela, Los invisibles. Para decirlo de otra manera, las novelas de Puenzo parecen realistas, pero en algún punto la mirada lectora sospecha que la narración de los hechos que está leyendo participa de otro tipo de lógica que pone en vilo el supuesto realismo narrativo del texto ${ }^{10}$. Funciona como una forma de contaminación entre un lenguaje que se presenta como transparente, y una estética que proviene de otro lado. Específicamente, de los medios masivos de comunicación: cine, televisión, historietas.

Por otro lado, el hecho de que Lucía Puenzo se encuentre inmersa en el mundo del cine o la televisión no se traslada de manera mecánica a sus

$9 \quad$ Lucía Puenzo es egresada de la Escuela Nacional de Experimentación y Realización Cinematográfica (ENERC), también estudió Letras en la UBA. El primer largometraje que dirigió, $X X Y$ (2007), obtuvo más de veinte premios internacionales. Es coguionista del documental (H) Historias cotidianas (Andrés Habegger, 2000), de los largometrajes La puta y la ballena (Luis Puenzo, 2003), A través de tus ojos (Rodrigo Fürth, 2006), El faro de las orcas (Gerardo Olivares, 2016); directora de los cortos Los invisibles (2008), Más adelante (2009) y de la serie para televisión Cromo (2015). Lleva publicadas seis novelas y un libro de relatos.

$10 \quad$ El tema del realismo en Puenzo es analizado por Carina González, quien estudia cómo en su narrativa se producen nuevos usos del realismo. Mediante la entrada de la oralidad, Puenzo introduce una forma de extrañamiento o de "deformación" de la materia narrativa que produce que el realismo se vea afectado, aunque no abandonado por completo. En gran medida, son los medios masivos los que proponen estrategias y convenciones genéricas que Puenzo traslada a la escritura como se ve, por ejemplo, en los manejos de las velocidades para la trama, así como los procedimientos en relación con el verosímil. En la escritura de Puenzo, según González, conviven un cierto giro documental, un ojo etnográfico orientado hacia lo popular, y una obsesión por mostrar determinadas “marcas generacionales" (194-198). 
textos, al menos en lo que concierne a lo argumental. La crítica a la televisión bajo la forma de cierto cruce entre esta y el mundo de la criminalidad, que aparecía como una breve pincelada en El niño pez, fue adquiriendo un creciente protagonismo en las siguientes novelas. En la segunda, 9 Minutos, la pareja protagonista de Iván y Uma son periodistas de televisión. Luego de haber estudiado la carrera de Letras, obtienen su éxito profesional en el show business televisivo. La crisis existencial narrada tiene mucho que ver con la visión del éxito que propone este ámbito. La cuestión de la televisión y sus lógicas mercantilistas retorna con mayor centralidad y virulencia en $L a$ maldición de Jacinta Pichimahuida. La novela se remite a Señorita Maestra, un programa televisivo de los años sesenta escrito por Abel Santa Cruz, y que tiene distintas versiones desde 1966 hasta 1985. Su intención no es homenajear al programa, sino hacer una sátira impiadosa al sistema de mercantilización neoliberal imbricado en la televisión, al que se le reprocha transformar todo lo que toca en mercancía. Mediante un juego entre dos líneas narrativas, una que se instala en el presente y otra en la época exitosa de su emisión, el texto parece estar imitando el recurso actual de la doble pantalla televisiva. No se ahorran críticas al comportamiento de todos los actores involucrados en el universo de la televisión, al que mediante diversos recursos narrativos y el personaje de Twiggy se termina equiparando con la industria del cine pornográfico. Este programa que ponía en escena una clase en una escuela primaria, con sus protagonistas infantes -a los que repetidamente se definía como las "dulces palomitas"-, muestra las peores dinámicas que tienen lugar en sus entretelones y que dejan al descubierto una industria siniestra. La furia de la langosta vuelve al tema de la crítica a la televisión (en tanto que industria y dispositivo), pero lo hace de manera más realista y apunta a develarla como cómplice o contracara de un sistema mafioso. Por último, el asunto del funcionamiento del sistema televisivo desaparece en Wakolda, novela que transcurre en los años sesenta en donde todavía su presencia es demasiado incipiente para cumplir un rol central, sea en la vida familiar o en el entramado social.

Recién en su libro de textos breves En el hotel cápsula, el cine está presente como tópico al que se recurre para llevar adelante lo narrado ${ }^{11}$. Lo que fue mencionado como pacto "autoficcional" se debe a que los tres textos tienen

11 El cine nunca aparece tematizado en sus obras previas, ni en las novelas ni en las películas. Eso no quiere decir que ellas no estén impregnadas y atravesadas por la estética 
como narradora al "personaje" de Lucía Puenzo en su carácter de directora de cine que viaja a causa de su trabajo. Son tres viajes a lugares -más o menosexóticos: Tailandia, Cuba, Japón. En los tres casos, la mirada subraya ese exotismo al posicionarse desde el lugar de observadora extrañada. A partir de cierto alejamiento, la narradora intenta comprender aspectos de otras culturas que a ella se le hacen, si no indescifrables, al menos diferentes. El primer texto es "Tai Toom", que transcurre durante unas horas en la ciudad de Bangkok a la que la directora de cine llega para la presentación de su película $X X Y$ en un festival. Allí es recibida por el embajador argentino que pasa a buscarla por el aeropuerto y la hospeda en la residencia de la embajada. La historia pronto adquiere una deriva que tiene menos que ver con la ciudad como con la hija trans del embajador. Estamos ante una historia de lo que sienten y piensan no solo esta hija sino su padre ante una serie de decisiones de trascendencia para ambos. El argumento se confunde con el de la película mencionada, $X X Y$, pero no alcanza su dramatismo ${ }^{12}$. Tailandia, a pesar del atentado terrorista islámico que está como telón de fondo y que pone en peligro al festival, es descrito como un lugar que ofrece un marco de inteligibilidad para la historia de Tai y de su padre. El mito de los "kathey", seres andróginos, quienes aparecen en la mitología tailandesa desde el origen de la creación junto al varón y a la mujer primordiales, permite que esa sociedad ofrezca acogida a les otres. Por ejemplo, a Nong Toom, un famoso boxeador trans que hacia el final del relato queda prendado de Tai, lo que da sentido al título.

El segundo relato, "Cohiba", como su nombre delata, tiene por escenario La Habana a donde la narradora va para hacer un seminario en la reconocida escuela de cine dirigida por Gabriel García Márquez. Es insoslayable cierto grado de parodia hacia esta figura "maestra" por la manera en que los participantes del seminario son utilizados para ofrendar sus historias al altar del patriarca. Las aventuras compartidas con sus compañeros (una

cinematográfica, bajo la forma de los géneros que cita de manera más o menos velada, desde el policial hasta el melodrama.

12 Son los dos casos en la obra de Puenzo en donde adquiere protagonismo un sujeto trans o intersexual. En los dos casos se aborda el deseo de superar el binarismo masculino/ femenino, sea mediante una nueva performance de género, como en el caso de Tai (Tiano), el hijo del embajador, o de Alex, el intersexual protagonista de la película $X X Y$, que plantea la libertad de elegir una posible definición sexual. Tai es el nombre que adopta esta chica trans de dieciocho años y que se encuentra transicionando. Por momentos se presenta todavía como Tiano. 
brasilera, un vasco y una húngara) duran poco, al igual que el seminario. La convivencia se arma y se desarma como una fugaz tormenta de verano. La historia adquiere ribetes policiales inesperados hacia el final. En un clima tórrido caribeño, marcado por los excesos típicos a los que invitan el clima tropical y los tradicionales productos de la isla (ron, habanos, salsa, etcétera), el lugar fronterizo aquí estaría situado en los lugares de lo permitido o no a propósito del ejercicio lícito de la sexualidad. El texto se propone interrogantes en torno a la cuestión del consentimiento para una relación sexual y del funcionamiento de las fronteras entre los cuerpos. Explora los matices inherentes a los diversos modos del rozamiento, que demarcan el límite a veces difuso entre los contactos placenteros y el terreno del abuso, entre la relación consensuada y la violación. De manera sutil, la mirada se concentra en el sistema patriarcal y sus movimientos que, de tan habituales, ya son imperceptibles. Sin decirlo de modo taxativo, está hablando acerca de las violencias que pueden constituir los pasos previos hacia el femicidio.

Para la tercera historia, "En el hotel cápsula", somos trasladados a Japón. La narradora transita entre Tokio y Kioto. De entrada, demarca las diferencias entre dos puntas extremas en las que se mueve la cultura japonesa: tradición y modernidad. También se puede pensar en un contraste intenso entre la espiritualidad (que ofrece el budismo) y el materialismo de la sociedad de consumo contemporánea. Todo junto, en los espacios reducidos característicos de Japón. Tokio es una ciudad alucinante y alucinada, llena de excesos y de estímulos, que hacen pensar en la película Blade Runner: "Tokio se tragó la tranquilidad del templo de un bocado: ahí estaban los rascacielos envueltos en cientos de pantallas, carteles inteligentes, neones que desde las alturas escupían estallidos de color para ganarse la atención de los que circulábamos abajo" (Puenzo 2017, 82). Kioto, por el contrario, funciona para la narradora como un espacio que la lleva a un tiempo detenido dentro del convento en el que es invitada para hacer meditación por un monje budista amigo de la madre. La protagonista oscila, aquí, entre el furor de la ciudad y la calma de este reducto. Entre uno y otro, encuentra una forma de no-lugar en el Shinjuku Capsule Hotel del título. Con su estética impoluta, indiferente -justamentea las diferencias, este hotel de paso se ubica en un espacio liminal entre un universo futurista, ascético a su manera, y la nostalgia del contacto. Qué otra cosa sino el deseo de recuperar algo perdido es el "fetiche" de las bombachas encapsuladas que llama la atención de la narradora, y en torno de la que gira la historia de Ryo, el conserje de ese hotel. Una historia entrevista como a través de una persiana es la que tiene lugar ante la mirada algo extraviada 
por la morfina de la narradora. Esta anécdota parece un homenaje al cineasta chino Won Kar Wai, con sus fábulas de amor teñidas de intensa melancolía.

Una primera lectura de estos textos nos presenta a un típico sujeto contemporáneo, que suele ser definido de modo algo grandilocuente como "ciudadano del mundo" 13 . Es uno que se mueve con comodidad entre los nolugares, sean estos aeropuertos, hoteles, trenes y aviones, centros comerciales, etcétera. Este sujeto puede atravesar las fronteras espaciales y culturales sin mayores dificultades enarbolando su pasaporte. Siempre hay modos de hacerse entender, aun sin compartir el idioma. Tal vez no sea un dato menor que este sujeto sea leído en clave femenina y que en los tres textos la sexualidad esté en el centro de la narración, así como atravesando numerosos debates actuales: sexualidades disidentes, machismo y patriarcado, prostitución, formas alternativas de vivir la sexualidad. En esta serie de textos, entramos medianamente engañados a historias que son más que plausibles o verosímiles. Sin embargo, en un punto las narraciones se deslizan de modo imperceptible a otros universos en los que también estamos inmersos, mundos virtuales que acompañan nuestro día a día y nos llenan de información más o menos útil. Dicha información cimienta una falsa certeza: la de que el mundo se nos abre, se hace pequeño como para que lo sostengamos en la palma de la mano, como anuncian triunfalistas las publicidades de turismo o de líneas aéreas. Si bien no hay una declaración de principios al respecto en los textos de En el hotel cápsula, ni siquiera expresada mediante los personajes, la melancolía o el desconcierto que tiñen los relatos dan pie para pensar nuevamente en lo que se esconde tras los ciertos discursos entusiastas.

La narradora de los tres textos que, en virtud de un artilugio narrativo, coincide con el sujeto autoral (la directora de cine Lucía Puenzo que viaja por trabajo o como consecuencia de él), se posiciona en un espacio que juega con la idea de lo intersticial, consciente de lo que implica sostener la mirada y narrar desde allí. Es evidente que su métier como directora de cine la hace

13 La aplicación de la idea de "sujetos nómades" (aporte de Rosi Braidotti), para abordar los personajes de Puenzo, ya había sido realizada por Anna Forné en un artículo en el que analizaba las dos versiones de El niño pez y la película $X X Y$, razón por la que no volvemos a ella. Forné piensa ciertos personajes como "figuras nómades" porque en ellas se proyectan "los intentos contemporáneos de disolución de una serie de dicotomías hegemónicas" (151), tales como género/sexualidad, humanidad/animalidad, naturaleza/cultura. El tópico del viaje sirve para explorar las tensiones y desplazamientos entre estos sistemas de oposiciones, así como posibles "líneas de desfiguración” (161). 
particularmente sensible a la noción de mirada. La autora, más allá de poner por escrito experiencias de viaje, está apelando a una fantasía que tiene que ver con la figura del cíborg, de la fusión entre especie humana y máquina. El realismo de su estética, así como el juego autoficcional, habilitan la posibilidad de pensar que, mediante la escritura, la voz narradora registra historias como si las mirara a través de la lente de una cámara de cine: "Me di vuelta y vi cientos de brazos levantados: agitaban billetes, las caras rojas, las venas hinchadas, gritando sus apuestas enardecidos, ahora que todo ahí adentro era cuestión de vida o muerte" (Puenzo 2017, 44). Sin embargo, este cuerpo al que se coloca como intermediario, hace pensable imaginarlo como una figura más compleja que la del mero ojo-máquina que registra, sucedáneo maquínico de un "narrador testigo". Se trata de un cuerpo-pantalla que separa dos mundos, el de este lado y el del otro lado de la cámara, como una membrana que no solo refleja, sino que actúa como frontera porosa y voluble entre imagen y escritura, entre este mundo y el otro. Son, tal vez, nuevos modos de ver las historias de siempre, la idea de que somos seres vulnerables. Es decir, que existimos en relación intrínseca e inevitable con los otros.

\section{GIRAR EL MAPA: $A L G U ́ N L U G A R$ DE PALOMA VIDAL}

En un texto publicado en la revista Zama, la escritora Paloma Vidal tomaba como punto de partida la pregunta de cómo girar los mapas sin la brújula del nacionalismo (130). Para su reflexión, esto supone pensar los movimientos que los sujetos realizan entre territorios, travesías que incluyen mucho más que la traslación física. Implica, en primer, lugar tener que lidiar con los imaginarios, con los sistemas de fantasías que funcionan en relación con culturas en mayor o menor medida vecinas. En ese contexto, Brasil se presenta como el territorio exótico por excelencia desde el punto de vista de un/a argentino/a. La pregunta de Vidal apuntaba en dirección a los condicionamientos que nos imponen las fronteras nacionales en la percepción de ese otro lugar, que se convierte -antes de existir materialmente- en un lugar Otro. Pero, además, llegar a lo otro no supone meramente un reajuste de la percepción con que se lo mira. Implica aceptar la propia condición de "inadecuado". En definitiva, como constata Vidal citando al crítico Raúl Antelo, se trata de llegar a lo propio por vía de lo ajeno. Ese es el gesto de "girar el mapa. Torcerlo, como una cinta de Moebius, para desorientar la brújula nacionalista" (Vidal, "Y el origen siempre se pierde" 133). La ficción, según Vidal, ofrece esos mapas 
-inventados, imaginados-, porque es la instancia que permanece "siempre alerta" ante las fallas de la realidad (134).

Este acto de girar el mapa es el que la autora realiza en su novela Algún lugar, publicada en castellano en el año 2017, en su portugués original en el 2009. Se trata de un periplo que va de sur a norte, si es que todavía confiamos en el mapamundi. Es decir, de la ciudad de residencia de la autora (su hogar), Rio de Janeiro, a la ciudad de Los Ángeles ${ }^{14}$. En este caso, lo exótico pasa a ser encarnado por esta megalópolis con fuerte presencia en los imaginarios globales a partir de la difusión que le dan los medios masivos, en especial, el cine. Aparece, nuevamente, el recurso de la autoficción, esta vez como la narración de un viaje que implica mucho más que la mera travesía turística. En este caso, el texto evoca al género del diario íntimo en este relato que da cuenta del año en que la autora y su pareja M pasan en Los Ángeles. La mudanza temporaria a esa ciudad tiene el objetivo de escribir una tesis de doctorado. En gran medida, esta historia es representativa de una circunstancia que se ha vuelto moneda corriente para las presentes generaciones, la de realizar estudios en otros países, que hoy en día empieza ya desde la adolescencia. La historia da un nuevo giro cuando, luego de un regreso a Rio de Janeiro por el receso universitario que se suponía transitorio, se clausura la estadía de forma anticipada ante el embarazo de la protagonista.

La estructura del libro juega con una ilusión: la fantasía de la línea recta. Está dividido en tres partes: Los Ángeles-Rio de Janeiro-Los Ángeles. Pero ese final, no lleva al punto de partida. En realidad, lo que el texto parece poner en cuestión es la noción misma de movimiento. El epígrafe, tomado de Silvina Ocampo, ya nos alerta sobre esto al afirmar que: "Se llega a un lugar sin haber partido de otro, sin llegar". Está hablando de un punto fijo, en donde el sujeto parece funcionar como pivote. Ahora bien, ¿cuál es la naturaleza de ese punto? Porque no da la impresión de que se trate de una instancia estática. Parece actuar como el centro de una esfera que se encuentra

14 Paloma Vidal nació en Buenos Aires, pero vive en Brasil desde los dos años. Se graduó en Letras por la Universidad Federal de Rio de Janeiro. Hizo la maestría y el doctorado por la Pontificia Universidad Católica de Rio de Janeiro; y postdoctorados en la Université Paris 7-Diderot (2016), en la Universidade Estadual de Campinas y la Universidad de Brasilia. Desde el año 2009 trabaja como profesora de Teoría Literaria en la Universidad Federal de San Pablo, donde vive actualmente trabajando como escritora, profesora y traductora. Ha publicado cuentos, novelas, piezas de teatro, ensayos académicos y poesía. Ha sido traducida al castellano, inglés y francés. 
constantemente en movimiento, equidistante de sus lados, y que se mueve con ella. Volviendo al texto, la simulación a la que se somete al lector, parte del malentendido que propone pensar en Los Ángeles meramente como en una ciudad. Ese "Los Ángeles" del tercer apartado es y no es la ciudad a la que se tiene por sede de la meca del cine, en donde reside Hollywood. Porque, literalmente, se refiere a un cine. Esta sala, la del cine Los Ángeles, que ya no existe más, se encontraba en la zona céntrica de otra ciudad, Buenos Aires, y se especializaba en pasar películas infantiles, básicamente filmes de Disney. Entonces, el relato hace un rulo en la travesía, como un desvío. De ese modo, desafía la línea recta, como una respuesta a esas líneas que la protagonista busca en la auténtica ciudad de Los Ángeles, en la que resulta imposible caminar mediante el sistema de calles o avenidas. La ciudad, con su "geometría cinematográfica" (17), permite circular solo a través de las "freeways", como constata la narradora al poco tiempo de llegar.

La protagonista da cuenta mediante su relato de la zozobra que le produce vivir en Los Ángeles, ciudad que conoce y desconoce a la vez. Al poco de haber arribado, se topa con la certeza de que "todo ya fue visto en otro lugar fuera de ahí" (17). El dejá vu que generan los paisajes norteamericanos para esta narradora traduce la impresión de que ya vio todo antes en innumerables películas y en la televisión. La extrañeza que le produce ese lugar parece incompatible con la familiaridad con la que ella supone que debería abordar esa ciudad extranjera. La vida cotidiana se ve atravesada por permanentes acomodamientos: a los medios de transporte, al idioma, a los usos del tiempo libre, a los espacios de trabajo y de esparcimiento. Incluso la visita a un museo, una actividad que forma parte del repertorio de cualquier ciudadanía contemporánea, se le convierte a la protagonista en una aventura con visos de safari al corazón de las tinieblas. Bajo las condiciones que ella misma se impone para llegar, es que nunca llega. Tampoco tiene éxito en establecer vínculos sustentables ni con los locales (su alumno Jay) ni con estudiantes que están en una situación similar a la suya (su compañera coreana Luci).

En ese entramado caótico de una megalópolis que pone al sujeto moderno en estado de perplejidad, la narradora encuentra una forma de guía en un texto de Walter Benjamin. En una de las primeras salidas que hace por su barrio entra a una pequeña librería. Ese primer descubrimiento le produce mucha alegría porque, como constatará poco más tarde, se encuentra en la base de la idea de "barrio", una localización que se supone debería dar anclaje al sujeto en la ciudad moderna. Cuando ella y su pareja sigan recorriendo lo que imaginan como su barrio, reconocer determinados negocios representa 
para ella subsanar la sensación de aislamiento que le transmite la dispersión de esa ciudad, al detectar cómo cubrir de manera inmediata sus necesidades: "Si llego a necesitar algo, ya sé dónde encontrarlo" (Vidal, Algún lugar 31). El problema es que la pequeña librería cierra al mes y medio, dejándola aún más desamparada. Pero en ese primer momento, la protagonista compra un ejemplar de Calle de mano única. Es un libro al que ella describirá como más subjetivo que crítico, o en el que subjetividad y crítica son una misma cosa. Esta anécdota sirve como guiño para entender la manera en que va a encarar la escritura del texto que tenemos en nuestras manos, porque el libro de Benjamin le ofrece "la posibilidad de otros métodos" (20). No es fortuito que cite a este filósofo en su confrontación con Los Ángeles. Sin embargo, la narradora no logra concretar allí la experiencia del flâneur, por lo que el texto de Benjamin no le sirve como brújula, sino que la obliga una vez más a girar el mapa ${ }^{15}$.

Exhibiendo hasta qué punto se aferra a un tipo de experiencias que son puestas a prueba por la ciudad monstruosa de Los Ángeles, su texto se abisma hacia lo íntimo y se vuelve fragmentario, como un pequeño rompecabezas que entrelaza vivencias y sueños. Atravesado una y otra vez por preguntas, nos va guiando por un laberinto que se parece cada vez más a un juego. Esas preguntas son como lanzaderas que van tramando un diálogo imaginario entre ella y su pareja, de ella consigo misma, de ella hacia quien lee: "¿Nuestro viaje será otra versión del sueño americano?” (22), ¿Qué te habías imaginado?” (33), “¿Dirías que soy inmigrante?” (44). Esos diálogos no pasan de la esfera de lo ficcional, pero suenan más reales que las conversaciones con las que los personajes dan verosimilitud a su convivencia en un mismo espacio, sea este el pequeño estudio en donde viven o en los claustros de la universidad. Una y otra vez, la protagonista parece confirmar que prevalece la desconexión.

El tema de la extranjería va en dos direcciones, porque no solo se remite a la instalación y/o adaptación a la nueva geografía. Un bagaje que la narradora ya trae consigo es el de su situación fronteriza en lo que concierne a su doble adscripción cultural. Porque si bien ella se reconoce como brasilera, en tanto

15 Por su parte, en el artículo de Correia Muzi et al., el texto de Benjamin es interpretado como una lectura en abismo o "espécie de sugestão metalinguística" (436) para la estructura narrativa de la novela. Así como Benjamin lee la ciudad moderna en sus características de alienante y fragmentada, se podría aplicar esta lectura a la ciudad de Los Ángeles que hace la protagonista y que además conlleva según las autoras una relativización del valor de la cultura literaria basada en el libro (436). 
que hija de argentinos expatriados participa de una doble matriz de pertenencia nacional. De hecho, ella siente su proximidad con lo argentino a través de algunos personajes con los que se topa o se encuentra en Los Ángeles. Un primer ejemplo sería el del médico que por casualidad se llama también Vidal y que le "declara" que "Los Ángeles es actualmente la ciudad con mayor cantidad de argentinos del mundo" (42), alimentando cierta mitología diaspórica tan apreciada por los argentinos. Otro ejemplo es Pablo, el profesor cordobés a cuyos cursos asiste la narradora, con el cual intercambia libros y con quien entabla lo que se ve como una amistad sincera. El español es, por cierto, su segunda lengua, lo cual le permite dar cursos de ese idioma en la universidad que la acoge, como parte de los programas de su doctorado a los que está obligada. No se pelea con este idioma como sí lo hace con el inglés. Cuando en la tercera parte de este libro-diario visite Buenos Aires con su hijo pequeño $\mathrm{C}$, la ciudad de donde es originaria su madre le resulta tanto o más familiar que Los Ángeles. Es una ciudad que lleva en sí una configuración fantasmática. En este caso, no responde a los imaginarios visuales sino a los recuerdos de infancia, a los momentos pasados con sus abuelos. El bilingüismo de su hijo le hará visible esta movilidad que ella le transmite como herencia.

La "brújula nacionalista" se ve, sin dudas, desorientada a partir de la experiencia de pluriculturalidad en la que vive la protagonista. De ahí que aparezca como pregunta recurrente la del significado de viajar. ¿Qué es viajar? ¿Por qué se viaja? Están los exilios (como el de sus padres), los deseos de liberarse del peso de la propia cultura (como le sucede a Luci), la pretensión de conocer otras culturas (como sostiene Jay), el trabajo o el estudio. La protagonista reconoce que a ella -a diferencia de su madre-, nunca le gustó viajar. Por eso, piensa la traslación a Los Ángeles en términos de "mudanza" y recuerda la nostalgia con la que su abuela le confesó que le "hubiera gustado viajar más" (127). Al final tiene que aceptar que el movimiento es inherente a la continuidad de la vida, al ver a su hijo que la saluda desde el caballo de la calesita "como si estuviera partiendo a un largo viaje" (155). Ese mismo hijo que con total naturalidad o desparpajo le plantea que quiere irse a otro lugar, sin un objetivo preciso. Simplemente ir a "Algún lugar" (145).

Pero no es la única desorientación a la que se refiere esta voz narradora. La sensación de estar a la deriva es evocada de manera constante para hacer referencia a varios tipos de vinculación con el entorno, como si fuera la condición natural de esta subjetividad. Estamos ante un sujeto desorientado con respecto a los lugares, a los otros, a la propia corporalidad. Se expresa 
como si estuviera todo el tiempo midiendo las distancias hacia el resto del mundo, así como las superficies de contacto con aquello que la circunda. En ese sentido, hace pensar en lo que plantea Sara Ahmed para los afectos y la manera en que estos moldean los cuerpos: "El cuerpo se abre a medida que el mundo se abre ante él; el cuerpo se desenvuelve en el desenvolverse de un mundo al que nos acercamos como si fuera otro cuerpo" (273). Ahmed sostiene que esas emociones que moldean las superficies mismas de los cuerpos no solo toman su forma a través de la repetición de acciones a lo largo del tiempo. Para el pensamiento de Ahmed, resultan fundamentales las orientaciones de acercamiento o alejamiento con respecto a los otros (24). La relacionalidad constituye un factor determinante, ya que es en virtud de las orientaciones de todo cuerpo que este se define en sus contornos tanto corporales como sociales. Es evidente, entonces, que este diario de viaje -travelogue o bitácora-, más que intentar dejar consignada una experiencia determinada (con sus observaciones, confrontaciones o meros apuntes), consiste en una hoja de medición de aquellos movimientos -orientaciones-, que van configurando la subjetividad en su contacto con el mundo circundante para llevar a cabo un mapeado del yo.

\section{TATUARSE EL MAPA EN EL CUERPO: $V$ DE MARIANA DOCAMPO}

En la primera novela de Mariana Docampo, El molino, aparecía el objeto material del mapa bajo una forma infanceada ${ }^{16}$, en lo que se presentaba como lo que Giuliana Bruno denomina un "mapa de las emociones"17. La

16 El término de "infanceada" está tomado del filósofo Walter Kohan a partir de sus reflexiones sobre la infancia como etapa (93-94). Kohan se remite a un tiempo que considera específico de la infancia, el de aión (el tiempo del acontecimiento). Vuelve a la conocida frase de Heráclito que dice que el tiempo es como un niño que juega. Kohan traduce con el término "infancear" al usado por Heráclito, "paizón", para referirse a otra lógica temporal que no es ni cronológica (es decir sucesiva), ni consecutiva, sino marcada por la idea de intensidad. Esta sería la lógica temporal de la infancia, caracterizada -antes que nada- por exhibir una relación diferente con el tiempo. Aquí se retoma para pensar una lógica alternativa a la adulta y para evocar la estética de ese período.

17 Giuliana Bruno usa la figura del mapa para pensar la conexión entre emoción y movimiento, en términos de cómo los cuerpos se mueven en el espacio y cuáles son las producciones culturales que reflejan ese vínculo. El objetivo de Bruno es mostrar la ligazón entre lo visual y cuestiones hápticas. 
protagonista-narradora dibujaba un croquis de un territorio que en cierto modo adquiría un carácter espectral. Lo hacía desde su presente del año 2005, al intentar reconstruir una serie de experiencias vividas durante la infancia, transcurridas entre los años 1979 y 1981. Ese mapa garabateado en un cuaderno evocaba el juego infantil del "ahorcado". Como se recordará, este juego consiste en reconstruir una palabra a la que le faltan casi todas las letras, salvo un par, al mismo tiempo que se va armando una figura que se representa -justamente- como ahorcada. El juego implica una carrera de supervivencia entre los oponentes (quien arma la palabra versus el que dibuja al ahorcado), en el tiempo que se despliega al tener que adivinar la palabra en cuestión. La metáfora del juego del ahorcado puede tener varias interpretaciones en la novela ${ }^{18}$. Pero, sobre todo, otorga una tesitura al recuerdo. Lo que importa retomar aquí es la idea del croquis, el dibujo espurio o provisorio, para delimitar algo sucedido en el pasado y así dar coto a una rememoración.

En este mapa dibujado por la narradora como una cifra de su acto de escribir, ella elige lo que serían los mojones de esa experiencia: el pequeño molino, el árbol del ahorcado, el estanque, la laguna de las ocas, el pantano, un cruce de caminos. Este mapa reúne en el papel los lugares físicos en donde la protagonista y su familia solían pasar los domingos en esos años vividos en la localidad de Zárate (en la provincia de Buenos Aires), experiencia que ella recuerda a partir de una mezcla de goce y de miedo, incorporados de forma equivalente. La etapa infante tramada por los juegos entre esos ocho hermanos y hermanas se ve atravesada por otras líneas, no tan amenas: los incipientes trastornos psíquicos del padre, la dura vida de la madre anegada por la maternidad, la política nacional en esos años del período del terrorismo de Estado en Argentina (1976-1983). Pero también supone una cartografía de sensaciones y afectos que configuran la subjetividad de esta mujer, que ella está buscando a través de la mirada lanzada hacia el pasado. Sobre todo, a los hechos vividos en los dos o tres años pasados en Zárate, en una casa con

18 La referencia al "ahorcado" tiene que ver con una anécdota que introduce el padre al llegar a ese árbol. El padre, que se pasaba contando historias de terror a los niños, les hace notar que en ese árbol se ahorcó el hijo de una vecina. Este rasgo subraya la falta de empatía del padre para con su familia, así como la tendencia a un histrionismo exacerbado, ambos síntomas de la perturbación mental que estallará más adelante. La narración va a ir introduciendo varios de estos elementos siniestros que bien puede reflejar el gusto por cierta imaginación "gótica" de la infancia, pero también esa atmósfera de lo Unheimlich. 
jardín y árboles y huerta. El mapa dibujado remite a los descampados a los que la familia iba los domingos, después de asistir a la misa, para hacer un picnic. Cartografiaba este paisaje que, a los ojos de la niña, era más salvaje y propicio para la aventura. El molino del título funciona como una especie de guía o referencia para orientarse en la planicie pampeana y es claramente retomado para organizar dichos recuerdos. Es decir, el molino adquiere cierto carácter totémico.

Entre la novela El molino y la última publicada, $V$, transcurren diez años y dos libros más, La fe y Tratado del movimiento. Es posible notar ciertas temáticas constantes u obsesiones en estos cuatro volúmenes. Reaparecen mostrando, no obstante, diversas modulaciones. Para el análisis de $V$ que nos interesa aquí, basta con enumerar las siguientes: la visión negativa de la figura del padre al que se retrata no solo como agresivo sino inmerso en una serie de trastornos psíquicos, un cuestionamiento con respecto al ejercicio de la maternidad, un sujeto infante sensibilizado ante los estímulos circundantes, el mundo natural muy presente bajo la forma de plantas y de animales (en especial, los pájaros), una preocupación constante por el cuidado del medio ambiente, una reflexión acerca de los modos que adquiere la creencia en una dimensión trascendente.

Por lo demás, estas dos novelas no pueden ser más diferentes. En El molino se respeta todavía un pacto realista de lectura. Allí es narrada la vida de esta familia católica numerosa desde la perspectiva de una de sus hijas, Juana, que reconstruye los años de infancia hilvanando diversas anécdotas familiares. $V$, por su parte, podría ser leída como una novela de ciencia ficción, aunque tampoco encaja por completo dentro de esta definición. El texto comienza centrado en lo que le sucede a $\mathrm{V}$, letra inicial para referirse a Verónica ${ }^{19}$. Esta mujer comienza un periplo de translación tanto física como psíquica que la llevará a transitar no solo por diversos estados de conciencia, sino también por diferentes estadios de la materia. No se trata de un mero caso de transmigración de almas, sino de otra cosa. V se multiplica. Se

19 En una entrevista que da para el programa En la Biblioteca dirigido por Irene Chikiar Bauer y que se puede ver en YouTube, Docampo aclara que la elección de ese nombre se debe a la película La doble vida de Verónica de Krysztof Kiéslowski. Es una forma de homenaje a la película, pero también le atrae la historia de una mujer que puede vivir dos avatares de una existencia paralela. En cuanto al subgénero de la novela, afirma que le interesaba trabajar el borde entre lo fantástico y lo realista, consciente de la no pertenencia ni a uno ni al otro género. Sobre todo, su idea era cuestionar las nociones de sujeto único y de tiempo lineal. 
percibe como un sujeto que ha perdido el anclaje en una subjetividad única para pasar a desplegarse en sus posibles y numerosos avatares, transexuales e incluso más allá de la especie.

La travesía que lleva a cabo esta subjetividad migrante obliga a repensar las categorías de tiempo y espacio. Si esta V(erónica) comienza su periplo en un tiempo y lugar reconocibles, la ciudad suiza de Lucerna y un presente ubicado en la actualidad, pronto saldrá disparada a una deriva narrativa que la llevará a atravesar desde los espacios microscópicos de la bacteria hasta las dimensiones inabarcables del universo interestelar; desde los pasados más remotos en donde todavía la especie humana no hollaba la tierra, hasta futuros imaginables más o menos lejanos, casi siempre distópicos. Como constata la voz narradora, el tiempo se abisma en un punto 0 , lo que da lugar a otro tipo de temporalidad no organizado de manera lineal:

El punto 0 marca el cambio de estado en cada una de las vidas de V. El tiempo anterior en el destino individual es un trazo único, discernible y completo. Pudo haber durado años o días, y puede no haber sucedido aún. Pero todas las secuencias confluyen en 0 , nexo que las articula. La identidad de V no es infinita, pero sí tan vasta que se ve obligad $x$ a hacer agrupaciones temporales de su yo para ordenar su experiencia. El tiempo no avanza. A partir de ahora, $\mathrm{V}$ transitará siempre el punto 0. (Docampo $V, 45$ )

Esta cita que ocupa todo el espacio de la página 45 (es la página 45), sugiere pensar a $\mathrm{V}$ ya no desde una subjetividad configurada narrativamente, sino en tanto que información. Remite a lo que Paula Sibilia propone como figura del "hombre postorgánico", es decir, una comprensión del cuerpo humano en donde prima un modelo tomado de la informática. Diseña una nueva figura en donde la configuración biológica se cruza con la digitalización.

La narración propuesta en $V$ sugiere ese deseo (o ansiedad) de lograr la compatibilidad entre cuerpos y tecnocosmos digital diagnosticada por Sibilia. Lo que Sibilia explicita es la manera en que los cuerpos contemporáneos se presentan como sistemas de procesamiento de datos, códigos, perfiles cifrados, bancos de información. Pasamos de pensar al ser humano como máquina, para verlo a través del código cifrado en el ADN. Esto adjudica a los cuerpos un carácter de permeables, proyectables, programables. El pasaje a la realidad virtual resultado de la actual forma del capitalismo globalizado y postindustrial conlleva una esperable reconfiguración en los modos de pensar al sujeto, algo que estaría cobrando forma en el texto de Docampo. 
Cabe preguntarse si la translación que ya no es espacial (¿habría que llamarla "especial"?) implica una aspiración de lograr un "upgrade", lo que Sibilia interpreta como una forma de tiranía contemporánea a la que se somete a los cuerpos (13). Pero que puede ser también un deseo de llevar a otro nivel a esos mismos cuerpos con la aspiración más o menos explícita de alcanzar otros modos de "habitabilidad", en términos de Judith Butler. Respondería no tanto a un desvanecimiento del sujeto sino a la propuesta de lanzarlo a una deriva que es en sí misma queer. Esto explica, en cierto modo, el estallido cronotópico de la novela. El relato se construye a partir de un movimiento que deja tras de sí una constelación estelar: varios segmentos de historias que se cruzan entre sí, núcleos narrativos en torno de los cuales se arman otras series, un retorno al esquema de la "novela familiar" (tan freudiana ella) en clave paródica y queer ${ }^{20}$.

La espacialidad en esta novela se arma a partir de los parámetros mediante los que la geógrafa feminista Doreen Massey piensa la dimensión espacial. En su intención de evitar una manera estática de encararlo y que tiende a fijarlo o cerrarlo, Massey piensa al espacio desde nociones tales como heterogeneidad, relacionalidad y contemporaneidad. Fundamental para ella es tener en cuenta que el espacio es producto de interacciones: "El espacio, así, es el producto de las intrincaciones y complejidades, los entrecruzamientos y las desconexiones, de las relaciones, desde lo cósmico, inimaginable, hasta lo más íntimo y diminuto. El espacio, para decirlo una vez más, es el producto de las interrelaciones" (115). En segundo lugar, Massey invita a tener en cuenta que el espacio existe en virtud de la coexistencia de la multiplicidad, la conjunción de distintas trayectorias: espacio y multiplicidad son dos dimensiones que están en relación de mutua dependencia. Por último, una consecuencia de estas dos premisas es que el espacio se encuentra en un proceso de permanente realización, un devenir nunca acabado ni cerrado.

20 Hay dos momentos en la novela en donde se recurre a la explicación familiar. Primero, cuando todavía se puede pensar al texto como la historia de Verónica y de lo que la condujo a su extraña transmutación, es decir, como la búsqueda de una causalidad en la enfermedad de Verónica siendo niña, sea en el rol cumplido por la genética o por el embarazo sobre este cuerpo. Aquí el texto se vuelve biopolítico. Luego hay una segunda "novela familiar" en el capítulo que va de la página 63 a la 72, en donde aparece otro avatar de V enfermo de poliomielitis. Esta historia que oscila entre el melodrama kitsch y la estética de los medios masivos (historietas, televisión, cine), evoca las novelas de Manuel Puig, sobre todo Pubis angelical (1979). 
De ahí que siempre suponga lo impredecible, el elemento de lo caótico o no prescripto por el sistema. La novela de Mariana Docampo parece responder a la exigencia de Massey de generar una "nueva imaginación geográfica" (118), que es claramente ficcional, pero ofrece formas alternativas de cartografiar al sujeto del postmilenio. $V$ propone una fantasía en donde este sujeto ya no sujetado a categorías como unicidad, sexo o especie, se expande siguiendo otra figura que es la del holograma. Resulta queer, no tanto porque puede ser varón o mujer, animal o humano, sino porque se expande en derivas inesperadas, no cartografiadas aún. La única manera de seguir su travesía es a través de las líneas que se demarcan mediante sus cambiantes delimitaciones corporales.

\section{CONCLUSIONES}

La primera dicotomía que se establece al pensar el movimiento tiene que ver con la quietud, la stasis. Y, de inmediato, se la visualiza bajo la forma de un sistema organizado en círculos concéntricos: la casa-vale decir, el hogar-, la ciudad, la nación, etcétera. Como hace notar Sylvia Molloy, la mezcla, correlato de la puesta en movimiento, funciona como la contracara de ese sistema que, por otro lado, le es inherente: "La mezcla, el ir y venir, el switching pertenece al dominio de lo unheimliche que es, precisamente, lo que sacude la fundación de la casa" (15). Ponerse en movimiento implica desestabilizar ese fundamento, aunque eso no supone abandonarlo por completo, sino correrlo de su lugar establecido. De ahí que esa frontera en donde se tocan el adentro y el afuera exista como superposición, como espacio cambiante, como un lugar que también acoge. Es una de las conclusiones que saca Bauman al pensar en la fluidez y el carácter de líquido que, si bien por un lado disuelve lo emparentado con las certezas y permanencias, abre nuevas potencialidades para los sujetos. Constituye, por otro lado, una condición ineludible de los sujetos contemporáneos. La siguiente reflexión de Bauman, más allá de sus diagnósticos poco optimistas para el presente, parece reflejar con exactitud lo que proponen los textos de las tres escritoras analizadas:

El truco no es no tener hogar, sino tener muchos, y estar al mismo tiempo fuera y dentro de cada uno de ellos, combinar la intimidad con la mirada crítica de un ajeno, el involucramiento con el distanciamiento -un truco que las personas sedentarias tienen pocas posibilidades de aprender-. Aprenderlo es la oportunidad del exiliado: de alguien 
técnicamente exiliado -el que está en el lugar, pero no es de él(Modernidad líquida, 217. Cursivas en el original).

Dicha certeza, que se ve a través de la experiencia de tantas viajeras y mujeres cosmopolitas, podría ser revisada si complejizamos las nociones de espacio a las que estamos habituados. $\mathrm{O}$, mejor dicho, los relatos que surgen como consecuencia de las vivencias provocadas por viajes y traslaciones, por mudanzas y mutaciones, nos obligan a repensar aquello que entendemos por espacio, así como la vinculación de esta dimensión con la del tiempo. Nuestros paisajes actuales abundan en nuevas "cronografías" inseparables de otras cartografías que diseñan tantos pasos trashumantes, como analiza de modo exhaustivo la crítica Graciela Speranza en su libro Cronografias, publicado en el 2017. Otra vez, esta fecha, lo que habla de una simultaneidad de intereses ${ }^{21}$.

Las textualidades de estas autoras, bajo sus variados formatos que incluyen tanto lo visual como las inscripciones que los cuerpos producen en el espacio (sea la performance o la danza), "con sus propios modos de figurar el mundo en cartografías imaginarias" (Speranza, Atlas 17), reescriben mapas que ofrecen nuevas posibilidades para transitar el mundo contemporáneo, en forma imaginaria o no tanto. Nos obligan como lectores a pegar un salto entre las traslaciones posibles y las derivas que solo pueden tener lugar (por ahora) en la fantasía. El "viajar con" al que nos invitan Lucía Puenzo y Paloma Vidal mediante sus relatos de corte autoficcional hace pensar en que, más allá de que ser turista o extranjero es algo ya incorporado en la experiencia de todo sujeto en el siglo XXI, vivimos viajando desde hace un par de siglos a través de las diversas pantallas y dispositivos, como demuestra Giuliana Bruno. La aventura de recorrer tiempos y espacios virtuales como aquellos a los que accede la protagonista de la novela de Mariana Docampo, no ofrece demasiada resistencia a la imaginación. Es, tal vez, el avatar próximo de nosotros en nuestra condición de cosmonautas.

21 Speranza había abordado la cuestión del espacio en un libro anterior, Atlas portátil de América Latina, en donde retomaba el concepto de "montaje" de Aby Warburg (vía DidiHuberman) como metodología para pensar aquello que emerge de los intersticios que abren las imágenes. Speranza recurría a varias figuras que servían para pensar lo espacial, tales como los mapas, las ciudades, las redes, las constelaciones. Los artistas que ella presentaba a través de sus obras hacían estallar una concepción estática y orgánica del espacio, para poder imaginarlo de manera más dúctil y maleable, más apta para entender el mundo contemporáneo. 


\section{BIBLIOGRAFÍA}

Ahmed, Sara. La política cultural de las emociones. 2004. México DF: Universidad Nacional Autónoma de México, 2015.

Bauman, Zygmunt. 2000. Modernidad líquida. Buenos Aires: FCE, 2002.

1998. La globalización. Consecuencias humanas. Buenos Aires: FCE, Buenos Aires, 1999.

Bruno, Giuliana. Atlas of Emotion. Journeys in Art, Architecture, and Film. New York: Verso, 2002.

Butler, Judith. Deshacer el género. 2004. Barcelona: Paidós, 2006.

Chikiar Bauer, Irene. "Entrevista a Mariana Docampo". En la Biblioteca. 14 de octubre 2018. Accesible en YouTube.

Correia Muzi, Joyce Luciane, Wilma dos Santos Coqueiro y Lúcia Osana Zolin. "Narrativas da diáspora feminina contemporânea: uma leitura de Algum Lugar, de Paloma Vidal". Letrônica, Porto Alegre, v. 7, n. 1, jan. /jun. (2014): 435-451.

Docampo, Mariana. El molino. Buenos Aires: Bajo la Luna, 2007.

V. Buenos Aires: Bajo la luna, 2017.

Forné, Anna. "Anatomías del sujeto nómade en la obra de Lucía Puenzo". De nómades y migrantes. Desplazamientos en la literatura, el cine y el arte hispanoamericanos. Comps. Andrea Castro y Anna Forné. Rosario: Beatriz Viterbo, 2015. 151-167.

González, Carina. "Migración y oralidad: la vida animal en la novela El niño pez de Lucía Puenzo". Revista de Crítica Literaria Latinoamericana. Año XXXVII, No 74, LimaBoston, $2^{\circ}$ semestre (2011): 193-214.

Kohan, Walter. Infancia, politica y pensamiento. Ensayos de filosofía y educación. Buenos Aires: Del Estante, 2007.

Logie, Ilse. "Relatos autoficcionales de filiación que operan un descentramiento lingüístico: Lenta biografia de Sergio Chejfec, El espíritu de mis padres sigue subiendo en la lluvia de Patricio Pron y Más al sur de Paloma Vidal". La impronta autoficcional. (Re)fracciones del yo en la narrativa argentina contemporánea. Ed. José Manuel González Álvarez. Madrid/Frankfurt aM: Iberoamericana/Vervuert, 2018. 59-74.

Luengo, Ana. "Buenos Aires como prisión - Paraguay como utopía: formas de resistencia y la creación de espacios alternativos en Leonera (2008) y El niño pez (2009)". Revista Iberoamericana, Vol. LXXXIII, Núm. 258, enero-marzo (2017): 41-55.

Massey, Doreen. "La filosofía y la política de la espacialidad: algunas consideraciones". Pensar este tiempo. Espacios, afectos, pertenencias. Comp. Leonor Arfuch. Buenos Aires: Prometeo, 2014. 99-121.

Molloy, Silvia. Vivir entre lenguas. Buenos Aires: Eterna Cadencia, 2015.

Puenzo, Lucía. 9 Minutos. Rosario: Beatriz Viterbo, 2005.

El niño pez. 2004. Rosario: Beatriz Viterbo. 2008.

En el hotel cápsula. Buenos Aires: Mansalva, 2017.

La furia de la langosta. Buenos Aires: Mondadori, 2010. 
La maldición de Jacinta Pichimahuida. Buenos Aires: Interzona, 2007. Los invisibles. Buenos Aires: Tusquets, 2018.

Wakolda. Buenos Aires: Emecé, 2011.

Punte, María José. Topografias del estallido. Figuras de infancia en la literatura argentina. Buenos Aires: Corregidor, 2018.

Sibilia, Paula. El hombre postorgánico: cuerpo, subjetividad y tecnologías digitales. Buenos Aires: FCE, 2009.

Siganevich, Paula. "La lengua, lazo poético y afectivo con el territorio de origen: las viajeras Lina Meruane, Cynthia Rimsky y Paloma Vidal". La precariedad como experiencia de escritura. Buenos Aires: Editora Grumo, 2018. 113-120.

Speranza, Graciela. Atlas portátil de América Latina. Arte y ficciones errantes. Barcelona: Anagrama, 2012.

Cronografias. Arte y ficciones de un tiempo sin tiempo. Barcelona: Anagrama, 2017.

Vidal, Paloma. "Y el origen siempre se pierde". Zama No 8, Poéticas (2016): 129-130. Algún lugar. 2009. Buenos Aires: Dakota Editores, 2017. 